\title{
ОСНОВНЫЕ ВИДЫ И ХАРАКТЕРИСТИКИ ВИРТУАЛЬНЫХ ОРГАНИЗАЦИЙ В ЭКОНОМИКЕ
}

\section{(c) 2018 Хромов Иван Евгеньевич}

кандидат экономических наук, старший научный сотрудник Центральный экономико-математический институт РАН 117418, г. Москва, Нахимовский проспект, 47

E-mail:khromov_gaugn@mail.ru

Концепция виртуальной организации ещё развивается, и пока даже не существует общего определения этого понятия. Однако существует много реальных примеров функционирующих виртуальных организаций. В данной работе рассмотрены основные виды и характеристики виртуальных организаций.

Ключевые слова: виртуальная организация, организационная структура, виртуальный образ, альянс, виртуальная команда, виртуальные проекты, динамическая сеть, партнёрство, сокращение издержек, управление предприятием, проекты.

Виртуальная организация - это временное объединение независимых компаний - поставщиков, заказчиков и даже бывших конкурентов, связанных при помощи информационных технологий для обмена навыками, затратами и доступом к рынкам друг друга. У виртуальной организации зачастую нет ни центрального офиса, ни иерархии, ни вертикальной интеграции. Данное словосочетание часто используют для определения предприятий, действующих на виртуальных рынках и в сети Интернет, кроме того, виртуальные организации также обозначают как «сетевые предприятия», «виртуальные корпорации», «виртуальные предприятия».
Виртуальные организации, как правило, могут быть отнесены к одному из четырех типов:

1. Виртуальный образ (рис. 1):

Виртуальный образ - это воплощение невиртуальной организации в киберпространстве. Такой тип виртуальной организации создается для предоставления товаров и услуг клиентам через Интернет. Например, интернет-магазины.

2. Альянс (рис 2):

Это партнерство, где каждый партнер несет примерно равное количество обязательств по отношению в виртуальной организации. Партнеры образуют консорциум, состав которого может меняться для более точного соответствия

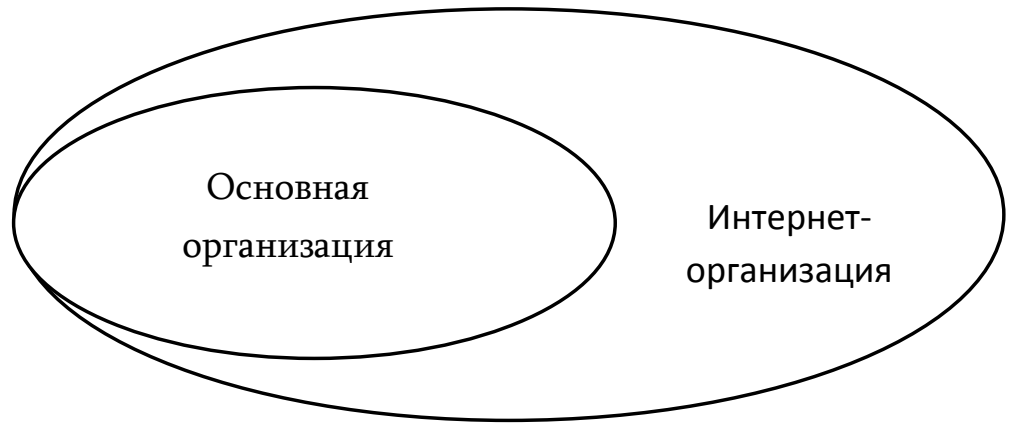

Puc. 1. Виртуальный образ

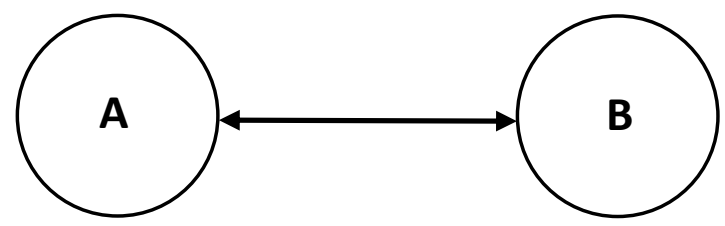

Puс. 2. Альянс 
рыночным возможностям или ключевым компетенциям каждого из членов альянса.

3. Альянс с лидирующей компанией (рис 3):

Это скоординированная сеть взаимосвязанных участников, представляющая собой ядро, окруженное спутниками. Ядром, как правило, является ведущее предприятие.

4. Альянс внутри цепочки создания стоимости (рис. 4):

Виртуальная организация подобного типа собирает широкий спектр поставщиков продуктов и услуг в один блок на основе цепочки создания стоимости. Координация внутри подобной модели обычно обеспечивается генеральным подрядчиком.

В случае, если отношения внутри организации приняли долгосрочный характер, то подобный альянс стремится принять форму альянса с лидирующей компанией, со сложными стратегическими отношениями между поставщиками
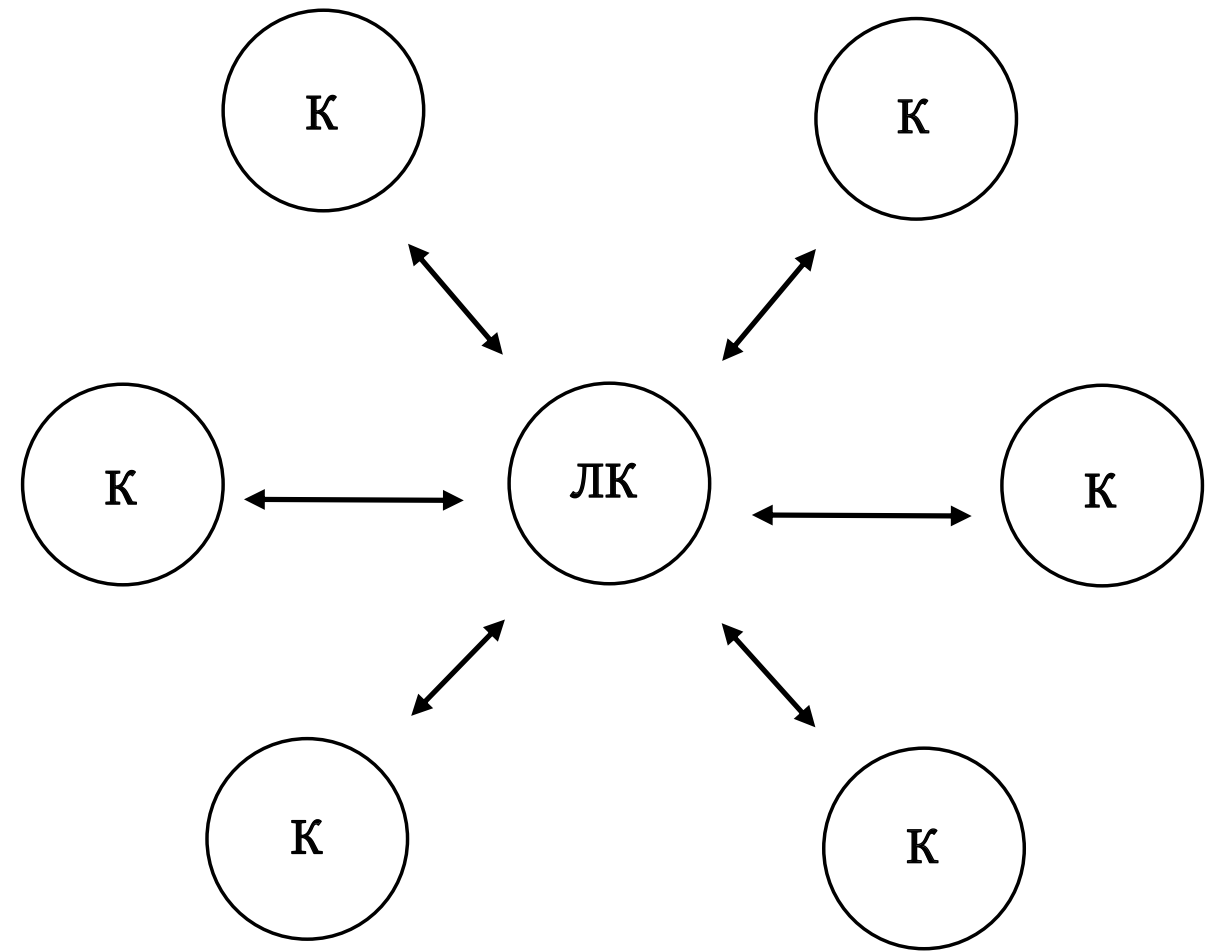

Рис. 3. Альянс с лидирующей компанией
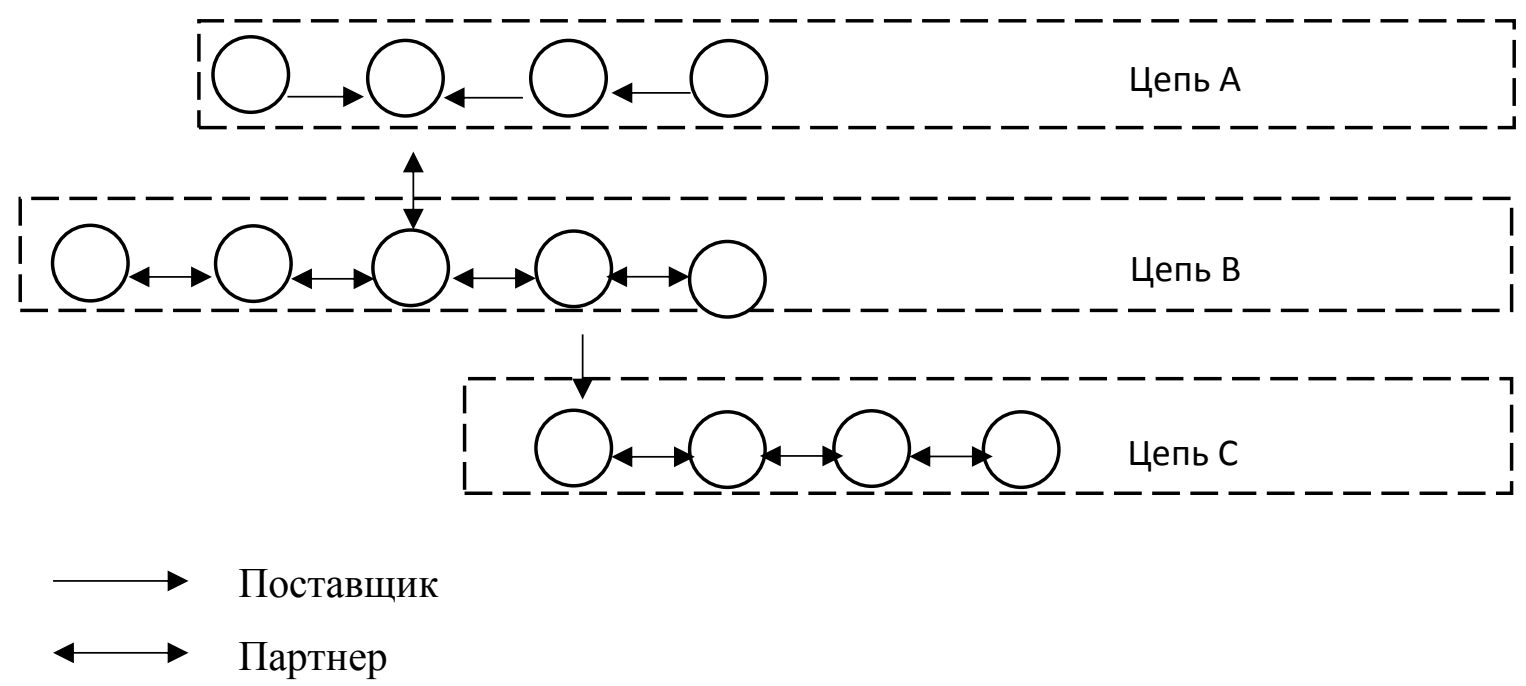

Puc. 4. Альянс внутри цепочки создания стоимости 
и компаниями внутри цепочки создания стоимости.

Так же, различают разные виды виртуальных организаций:

- Виртуальная команда.

Концепция виртуальных команд порождается внутриорганизационным использованием концепции виртуальной организации. Виртуальные команды обычно существуют для работы в рамках конкретного функционального, технологического или бизнес-процесса внутри организации.

\section{- Виртуальные проекты.}

Концепция виртуального проекта используется организациями, которые формируют альянсы или консорциумы, для того, чтобы объединять взаимодополняющих партнеров. Такой вид наиболее часто встречается среди виртуальных организаций, объединяющих подобные друг другу отрасли или типы предприятий.

- Временная виртуальная организация.

Временная виртуальная организация является вариацией виртуального проекта, созданного для конкретного проекта или решения определенной задачи. После завершения проекта такая виртуальная организация распадается.

- Постоянная виртуальная организация.

Постоянная виртуальная организация создается не на время конкретного проекта, как временная, но изменяется в соответствии с рынком, модернизируя приносящую доход деятельность.

Основными характеристиками, описывающими виртуальную организацию, являются:

1. Ключевые компетенции.

Выбор партнера для виртуальной организации основывается на его ключевых компетенциях. Инициатор объединения осуществляет выбор компаний-партнеров таким образом, чтобы их

Таблица 1. Сравнение видов виртуальных организаций

\begin{tabular}{|c|c|c|c|c|}
\hline & $\begin{array}{l}\text { Виртуальная } \\
\text { команда }\end{array}$ & Виртуальный проект & $\begin{array}{l}\text { Временная } \\
\text { виртуальная } \\
\text { организация }\end{array}$ & $\begin{array}{l}\text { Постоянная } \\
\text { виртуальная } \\
\text { организация }\end{array}$ \\
\hline $\begin{array}{l}\text { Границы } \\
\text { применения }\end{array}$ & $\begin{array}{l}\text { Внутренняя по } \\
\text { отношению к } \\
\text { организационной } \\
\text { функции или } \\
\text { ведомственной } \\
\text { единице }\end{array}$ & $\begin{array}{l}\text { Межфункциональная } \\
\text { и } \\
\text { межорганизационная }\end{array}$ & Межорганизационная & Межорганизационная \\
\hline Участники & $\begin{array}{l}\text { Маленькие, } \\
\text { местные }\end{array}$ & Любые & $\begin{array}{l}\text { Как правило, } \\
\text { большие }\end{array}$ & Небольшие \\
\hline $\begin{array}{l}\text { Область } \\
\text { применения }\end{array}$ & $\begin{array}{l}\text { Конкрентые, } \\
\text { текущие задачи }\end{array}$ & $\begin{array}{l}\text { Несколько партнеров, } \\
\text { работающих над } \\
\text { конкретными } \\
\text { проектами }\end{array}$ & $\begin{array}{l}\text { Многоцелевое } \\
\text { назначение, } \\
\text { соответствующее } \\
\text { рыночным } \\
\text { возможностям }\end{array}$ & $\begin{array}{l}\text { Может выполнять } \\
\text { любые функции или } \\
\text { использоваться как } \\
\text { отдельная } \\
\text { действующая } \\
\text { организация. }\end{array}$ \\
\hline $\begin{array}{l}\text { Продолжитель- } \\
\text { ность проекта }\end{array}$ & $\begin{array}{l}\text { Участники } \\
\text { меняются, но } \\
\text { форма остается } \\
\text { неизменной }\end{array}$ & Временная & Временная & Постоянная \\
\hline $\begin{array}{l}\text { Использование } \\
\text { ИТ }\end{array}$ & $\begin{array}{l}\text { Связь, } \\
\text { совместное } \\
\text { использование } \\
\text { общих знаний }\end{array}$ & $\begin{array}{l}\text { Хранилище общих } \\
\text { данных (базы } \\
\text { данных, общее } \\
\text { программное } \\
\text { обеспечение) }\end{array}$ & $\begin{array}{l}\text { Общая } \\
\text { инфраструктура } \\
\text { (программное } \\
\text { обеспечение, } \\
\text { глобальная } \\
\text { вычислительная } \\
\text { сеть) }\end{array}$ & $\begin{array}{l}\text { Канал для сбыта и } \\
\text { распределения - } \\
\text { замена физической } \\
\text { инфраструктуре } \\
\text { (интранет, интернет) }\end{array}$ \\
\hline
\end{tabular}


навыки были взаимодополняющими, что является важным для эффективного осуществления бизнес-процессов и позволяет наиболее полно удовлетворять потребности клиентов.

2. Сеть независимых организаций.

Виртуальные организации в экономической литературе, как правило, рассматриваются как сеть независимых организаций.

3. Идентифицируемость.

Виртуальная организация должна иметь свою собственную идентичность. При этом, если индивидуальность партнеров остается видимой, то такая виртуальная организация называется «мягкой виртуальной организацией», а в случае, если организация со стороны выглядит как единое целое, то такая организация называется «жесткой виртуальной организацией».

4. Основана на информационных технологиях.

Существует несколько различных взглядов на информационно-коммуникационные технологии, как на фактор создания виртуальных организаций. Так, важным считается развитие в области транспорта, связи и вычислительной техники. Так же информационная сеть рассматривается как основной способ объединения и работы компаний.

5. Отсутствие иерархии.

Равенство партнеров в виртуальной организации, как правило, приводит к отсутствию иерархии в организации. Иногда, такая структура организации обозначается как эгалитарная. Преимуществом подобной структуры является повышение эффективности и оперативности организации, и при этом - сокращение накладных расходов.

Так же существуют другие характеристики, которые, в отличие от ключевых факторов, не являются необходимыми для определения виртуальной организации.

1. Размер предприятий: небольшие компании и/или части крупных компаний.

Основную компетенцию партнера, в основном, представляет собой не вся компания в целом. Если это не небольшая компания, специализирующаяся на определенной деятельности. Меньший размер партнеров позволяет достичь большей гибкости и позволяет с большей легкостью пользоваться рыночными возможностями. Кроме того, некоторые авторы указывают на тот факт, что крупные компании часто медленнее в принятии решений и инноваций.

\section{2. Неопределенность границ.}

Эта характеристика означает, что существуют сложности в определении того, где начинается одна организация и заканчивается другая, когда речь идет о виртуальных организациях. Это является результатом глубокого сотрудничества между конкурентами, клиентами, поставщиками и так далее.

Различают внутренние и внешние границы, где внешние границы, между виртуальной организацией и остальным миром, противопоставляются границам между внутренними партнерами (частями) в виртуальной организации.

3. Полу-стабильные отношения.

Отношения между партнерами в виртуальной организации являются менее формальными и менее постоянными, чем в традиционной организации. Несмотря на то, что существование в рамках виртуальной организации вынуждает партнеров быть в какой-то степени зависимыми друг от друга, компании-партнеры могут существовать и без них.

4. Разделение рисков.

Возникновение виртуальной организации является реакцией на существующие на рынке возможности. Так как при увеличении рыночных возможностей, увеличиваются и риски, то для виртуальной организации является крайне важным разделение рисков между партнерами.

5. Основана на доверии.

Так как виртуальная организация основана на обмене информацией и знаниями, и каждый партнер вносит вклад в существование виртуальной организации через свои ключевые компетенции, то должна существовать высокая степень доверия между партнерами.

6. Совместное владение.

Эта характеристика связана с тем, что каждый независимый партнер имеет свои собственные интересы в виртуальной организации, и ее разные части могут находиться в собственности различных партнеров. Так же, это означает, что каждый из партнеров может выйти из организации, как только достигнет своей цели.

7. Разделенное руководство.

То, что каждый из партнеров контролирует свои собственные ресурсы, не означает, что, он контролирует ресурсы всей виртуальной организации.

8. Общая лояльность.

Наряду с общей собственностью приходит общая лояльность - каждый сотрудник каждо- 
го партнера в виртуальной организации должен идентифицировать себя как с этой виртуальной организацией, так и со своей собственной «внутренней» компанией. Что означает существование чувства коллективности, разделения целей.

9. Динамическая сеть.

Виртуальная организация зачастую описывается как динамическая сеть, что связано с тем, что компании и отдельные лица могут входить и выходить из организации в любое время.

10. Зависимость от инноваций.

Так как виртуальная организация часто основывается на рыночных возможностях и её существенным элементом является соответствующая отзывчивость, то наиболее адекватной реакцией на рыночный стимул, для виртуальной организации, будет является использование инновационных продуктов и услуг. Причем инноваций не только с технической точки зрения, но и, например, инноваций в области организационного проектирования.

11. Географическое рассредоточение.

Этот фактор является одним из наиболее важных для использования информационно-коммуникационных технологий в виртуальных организациях. Информационные технологии позволяют компаниям сотрудничать вне зависимости от места и времени, могут дать членам виртуальной команды ощущения присутствия и связи, даже если они находятся за много километров друг от друга.

12. Массовая кастомизация.

Создание индивидуальных услуг и продуктов для удовлетворения конкретных потребностей и пожеланий клиентов. Плотное взаимодействие с клиентом.
13. Продолжительность

сотрудничества: временное / постоянное.

Жизненный цикл виртуальных организаций широко обсуждается в литературе, однако большинство авторов определяют виртуальную организацию как временную сеть независимых партнеров. Такие партнеры быстро объединяются, используют появившиеся рыночные возможности и впоследствии расформировываются. Другие исследования используют интерпретацию виртуальных организаций как временное объединение, которое также может существовать и на постоянной основе.

Например, виртуальная организация может быть распущена в случае завершения проекта, но также может иметь неопределенную длительность существования в случае, если существует потребительский спрос или участники находят свое взаимодействие полезным.

14. Баланс сил: равные партнеры/ существование лидирующей компании.

Из-за высокой зависимости между партнерами в виртуальной организации участники становятся более равными между собой. Предшествующая культура управления заменяется культурой, основанной на желании разделить навыки и информацию.

В случае с организацией с лидирующим партнером, такой партнер будет являться своего рода «центром» виртуальной организации, которому должны подчиняться другие участники.

Стоит заметить, что, поскольку члены виртуальной организации могут быть партнерами в одном альянсе, но конкурентами в других, то они имеют меньше стимулов к тому, чтобы быть открытыми и свободно обмениваться данными.

\section{Библиографический список}

1. Bultje R., van WijkJ. Taxonomy of Virtual Organisations, based on definitions, characteristics and typology. VoNet: The Newsletter, 1998, № 2 (3).

2. Byrne J.A. The futurists who fathered the ideas. Business Week, 8 February 1993.

3. Chesbrough H.W., Teece D.J. When is Virtual Virtuous: Organizing for Innovation, in: Harvard Business Review, January-February 1996.

4. Davidow W., Malone M. The Virtual Corporation: Structuring and Revitalizing the Corporation for the 21 st Century. New York: Harper Collins, 1992.

5. Jägers, H., Jansen, W., Steenbakkers, W. Characteristics of Virtual Organizations. Organizational Virtualness, Proceedings of the VoNet - Workshop, April 27-28, 1998.

6. Mowshowitz, A. (1994). Virtual Organisation: A Vision of Management in the Information Age, in: The Information Society, 1994, Vol. 10.

7. Sieber P., Griese J. Organisation Virtualness, Proceedings of the VoNet-Workshop, Simowa Verlag Bern, Bern, April 1998. 